\title{
Bringing maker practices to school: tracing discursive and materially mediated aspects of student teams' collaborative making processes
}

\author{
Sini Riikonen $^{1}$ (D) $\cdot$ Pirita Seitamaa-Hakkarainen ${ }^{1} \cdot$ Kai Hakkarainen $^{1}$
}

Received: 8 April 2020 / Accepted: 25 August 2020 / Published online: 7 September 2020

(C) The Author(s) 2020

\begin{abstract}
The present investigation aimed to analyze the collaborative making processes and ways of organizing collaboration processes of five student teams. As a part of regular school work, the seventh-grade students were engaged in the use of traditional and digital fabrication technologies for inventing, designing, and making artifacts. To analyze complex, longitudinal collaborative making processes, we developed the visual Making-Process-Rug video analysis method, which enabled tracing intertwined with social-discursive and materially mediated making processes and zoomed in on the teams' efforts to organize their collaborative processes. The results indicated that four of the five teams were able to take on multifaceted epistemic and fabrication-related challenges and come up with novel co-inventions. The successful teams' social-discursive and embodied making actions supported each another. These teams dealt with the complexity of invention challenges by spending a great deal of their time in model making and digital experimentation, and their making process progressed iteratively. The development of adequate co-invention and well-organized collaboration processes appeared to be anchored in the team's shared epistemic object.
\end{abstract}

Keywords Co-invention $\cdot$ Collaborative making $\cdot$ Epistemic object $\cdot$ Knowledge-creating learning $\cdot$ Sociomateriality $\cdot$ Teamwork

Sini Riikonen

sini.riikonen@helsinki.fi

Pirita Seitamaa-Hakkarainen

pirita.seitamaa-hakkarainen@helsinki.fi

Kai Hakkarainen

kai.hakkarainen@helsinki.fi

1 University of Helsinki, Helsinki, Finland 


\section{Introduction}

This design-based investigation aimed to examine seventh-grade students' collaborative making processes and developed analytic methods for tracing socially and materially mediated aspects of their co-invention efforts. Productive participation in the emerging innovationdriven knowledge society requires that young people be socialized to expert-like creative practices of deliberately pursuing novelty and innovation rather than merely learning to reproduce what is already known (Paavola, Lipponen and Hakkarainen 2004). Within this development, investigators of computer-supported collaborative learning (CSCL) are increasingly interested in promoting and studying young students' invention processes in the context of science, technology, engineering, and math (STEAM) projects supported by digital fabrication tools (Blikstein 2013; Honey and Kanter 2013; Halverson and Sheridan 2014). Many studies on maker-centered learning (Clapp, Ross, Ryan, and Tishman 2016) also highlight the relevance of art, craft, and design for creative expression (Buchholz, Shively, Peppler, and Wohlwend 2014; Peppler, Halverson, and Kafai 2016). We maintain that maker-centered learning and associated integrative co-invention processes are becoming strategic components of future-oriented education. To examine such knowledge-creating learning processes, we engaged students in collaborative efforts for co-inventing and making materially embodied artifacts, sparking intellectual, technical, and aesthetic challenges.

Most studies on maker-centered learning have taken place in informal contexts rather than in schools. In order to elicit students' invention capabilities and provide more inspiring educational experiences, learning-by-making should, however, be rooted in schools (Blikstein 2013; Clapp, Ross, Ryan, and Tishman 2016). Rather than merely organizing makerspaces together with museums, libraries, and after-school programs (Gutwill, Hido, and Sindorf 2015; Halverson and Sheridan 2014), Finland and other Scandinavian countries have craft (sloyd) education as an obligatory school subject, with sophisticated craft- and science-lab spaces enabling the integration of collaborative making into core curricular activity (Seitamaa-Hakkarainen and Hakkarainen 2017). Although craft education has a long history in textile and technology education, integrating craft with digital fabrication technologies has only emerged recently. Traditional craft education and its possibilities for sociomaterially (Orlikowski and Scott 2008) mediated learning has neither received much academic attention nor been very appreciated. Nevertheless, the new Finnish basic education curriculum highlights collaborative learning, creative use of digital technologies, and integrative thematic (phenomenon-based) studies as frames in which challenging maker projects can be organized (Silander, Riikonen, Seitamaa-Hakkarainen and Hakkarainen, in press).

Our efforts focus on creating high-end makerspaces in Finnish schools by expanding craft classrooms through digital fabrication instruments, such as three-dimensional computer-aided design (3D CAD), robotics, electronic circuits, and wearable computing (e-textiles), with which one may create multi-faceted and relatively complex artifacts (cf. Blikstein 2013; Gutwill et al. 2015). Although invention projects taking place in many makerspaces are personal rather than collaborative, we consider it pedagogically critical to engage student makers in collaborative teamwork. In accordance with craft tradition, collaborative making projects are 1) multi-material, including both soft (e.g., textile) and hard (e.g., metals) materials; 2) digitally enhanced (integrating digital devices and applications); 3) holistic in terms of including all stages of creation from design ideation to experimentation, and from 
fabrication to evaluation of the final productions; and c) anchored on integrative thematic study projects orchestrated by teacher teams representing multiple subject domains (SeitamaaHakkarainen and Hakkarainen 2017).

One methodological challenge of studying maker-centered learning is that making happens "around" rather than "through" CSCL technologies (Stahl and Hakkarainen 2020). While many traditional CSCL environments provide built-in analytic instruments and methods, maker-centered learning involves opportunistic utilization of diverse traditional and digital tools and resources that vary across heterogeneous projects in oftentimes surprising ways. Because longitudinal collaborative maker projects are complex and very laborious to investigate, many educational maker studies take the form of descriptive case studies. Although such studies are inspiring and provide valuable information about emergent making practices, large-scale implementation of maker practices in formal education requires the development of systematic analytic methods that allow longstanding making processes to be traced and compared across teams, schools, and levels of education. To solve the above challenges, we developed the Making-Process-Rug video analysis method, which helped us to trace sociomaterially intertwined, socialdiscursive, materially mediated, individual, and collaborative making processes across different phases of the co-invention process. The analysis method enabled the construction of a comprehensive macro-level overview of how collaborative making proceeds over time through discussing, sketching, prototyping, and using tools and materials. It also helped us zoom into the intermediate and micro levels to examine how invention teams organized their collaboration processes. We used the Making-Process-Rug method to analyze qualitatively five seventh-grade (aged 13 to 14) student teams' longitudinal collaborative making activities and the ways in which the students organized the joint making processes.

In the remainder of the article, we will first present the theoretical framework of our investigations. Then, we will describe the research setting, the methods of data collection, and the video analysis method developed for this study. Finally, we will present our results and discuss the significance of the findings.

\section{Creating knowledge through collaborative making processes}

The present investigation relies on our longstanding effort to cultivate knowledge-creating learning (Paavola, Lipponen and Hakkarainen 2004), which, beyond knowledge acquisition and social participation, involves systematic collaborative efforts to create and advance knowledge by creating materially embodied artifacts. The dominating CSCL pedagogies for fostering knowledge-creating learning at school have, however, focused on either students' meaning-making discourse interaction (Andriessen, Baker and Suthers, 2003) or collaborative building of conceptual knowledge (Scardamalia and Bereiter 2014a) mediated by corresponding CSCL tools. In spite of pioneering investigations by Papert (1980) and his followers (Blikstein 2013; Kafai 2006), school education has not extensively capitalized on learning from the collaborative making of embodied artifacts.

Previous studies suggest that the collaborative creation of novelty requires group members to focus on a shared epistemic object and the socially shared regulation of the joint process (Damsa, Kirscher, Andriessen, Erkens, and Sins 2010; Järvelä, Järvenoja, Malmberg, and Hadwin 2013). Epistemic objects are envisioned as well as future-oriented invention ideas, 
which are characterized by their incompleteness and infinite potential for improvement through sustained iterative efforts (Ewenstein and Whyte 2009; Knorr-Cetina 2001). Learning by collaborative making entails, in accordance with Papert's (1980) constructionism, that learners use digital and traditional instruments to jointly invent, design, and make materially embodied artifacts, cultivating new ways of thinking and acting during the process (e.g., Blikstein 2013; Kafai 1996; Kafai, Ah, Fields, Ristin, and Searle 2014). Collaborative making involves students materializing their ideas through conceptual (spoken or written ideas), visual (drawing, sketches), or material (3D prototypes and models) artifacts, creating an opportunity for themselves and their peers to build on these external objects and to discuss, elaborate, and refine them (Kangas, Seitamaa-Hakkarainen and Hakkarainen 2013). Accordingly, collaborative making involves interaction between ideas, traditional and digital instruments, materials, socio-material spaces, and associated embodied experiences of refining and extending invented objects (Gutwill et al. 2015).

Furthermore, collaborative knowledge creation is an emergent and nonlinear process in which the goals pursued, objects iterated, stages reached, digital tools used, and resulting products cannot be pre-determined (Scardamalia and Bereiter 2014b, see also Härkki, Vartiainen, Seitamaa-Hakkarainen, and Hakkarainen, in press;). As such, collaborative making diverges radically from the typical highly scripted, closed, and reproductive learning tasks that dominate schooling (Seitamaa-Hakkarainen, Viilo and Hakkarainen 2010). Nonlinear pedagogy is called for by the new Finnish curriculum, which highlights the importance of integrative studies that focus on open-ended phenomena such as an invention challenge, complementing studies driven by pre-assigned curricular content (Silander, Riikonen, Seitamaa-Hakkarainen, and Hakkarainen, in press). We argue that collaborative making is an especially effective way of engaging students in "design mode" (Bereiter and Scardamalia 2003), leading them to continuously refine and improve the functional adequacy of ideas in development. Moreover, collaborative making affords the opportunity to devote sustained efforts in the further advancement of the objects being invented. We highlight, however, the epistemic value of parallel and successive social-discursive and materially mediated working with the targeted object because such sociomaterial activity expands the field of inventive activity and makes unforeseen affordances and possibilities actionable. Although all CSCL environments hybridize conceptual and material aspects of activity (Hakkarainen 2009), working with physical tools and materials and pursuit of material experimentation tends to be a peripheral aspect of inquiries driven by conceptual knowledge.

Usually, students have their most intensive experiences with the creative use of digital technologies outside of schools (Ito, Gutiérrez, Livingstone, Penuel, Rhodes, Salen, Schor, Sefton-Green and Watkins 2013), and longitudinal investigations reveal technology-oriented students become increasingly alienated and disengaged at school (Hietajärvi, Lonka, Hakkarainen, Alho and Salmela-Aro 2020). Our investigation indicates, however, that schools implementing maker-centered pedagogies provide students with more intensive structured support for learning creative practices of technology use than they encounter in informal contexts (Forsström, Korhonen, Tiippana, Sormunen, Juuti, Seitamaa-Hakkarainen, Lavonen and Hakkarainen, submitted). One of the rationales for extending maker culture to schools in the form of technology-mediated co-invention projects is to provide students with access to expert-like design, engineering, and scientific knowledge practices. We consider knowledge creation a practical communal activity that, to a significant extent, relies on operational methods, creative processes, and practices ("knowledge practices") that students and their communities can appropriate and cultivate with adequate facilitation, guidance, and real-time 
support (Ritella and Hakkarainen 2012). In the present case, the students were socialized to appropriate collaborative practices of making artifacts through iterative design, engineering, and making processes in which invention ideas were elaborated and refined through the analysis, evaluation, and deliberation of materialized ideas (Kangas, Seitamaa-Hakkarainen and Hakkarainen 2013). We argue that such expansive learning by making fosters a renaissance of practical thinking that is critical for students' creative engagement, positive treatment of cognitive diversity, and building of identity as a potential creator of knowledge.

\section{Organizing collaborative making processes to attain shared epistemic objects}

When developing maker pedagogies, it is essential to understand how students collaborate in a small group setting when pursuing open-ended co-invention challenges. Indeed, collaboration within student teams has been investigated rigorously, especially in relation to collaborative talk and action (e.g., Barron 2003; Buchholz et al. 2014; Ching and Kafai 2008; Linn 2006). In many cases, however, research into small student groups has been conducted in traditional classroom settings with reproductive learning tasks. Collaborative invention challenges put students and their teachers in a totally different situation, which may lead to overwhelming challenges as they are working with unfamiliar digital fabrication technologies, encountering unanticipated construction problems, and carrying out inquiries leading toward unforeseen directions. Because of the emergent nature of epistemic objects and the nonlinear nature of collaborative making, the process may be very challenging for the students, and it may also make the scaffolding of nonlinear processes perplexing for teachers (Härkki, Vartiainen Hakkarainen and Seitamaa-Hakkarainen, in press).

Our study examines collaboration as an activity in which students a) jointly regulate their activity as a team to attain a shared epistemic object and b) co-design their knowledge-creating inquiries, deliberately organize group processes to maintain a shared understanding of the unfolding invention process, and evaluate their progress toward the object (Damsa et al. 2010; Miyake and Kirschner 2014; Panadero and Järvelä 2015). We use the phrase process organizing (Lahti, Seitamaa-Hakkarainen and Hakkarainen 2004) to refer to such social-epistemic regulation of collaborative making processes. In order to successfully address an invention challenge, a team must simultaneously deal with various invention ideas and constraints inherent in making activities, and it must also organize, in real time, its ongoing collaborative process (Gutwill et al. 2015; Kangas, SeitamaaHakkarainen and Hakkarainen 2013). Focused, creative pursuit requires students to work actively toward a joint object, to listen, understand, and help each other, and to engage in shared efforts to construct and test the artifacts being developed.

Collaborative making is a sociomaterial process that entangles social-interactive processes with materially mediated processes (Mehto, Riikonen, Hakkarainen, Kangas and SeitamaaHakkarainen 2020; Orlikowski and Scott 2008). Sketches and prototypes provide material anchors for directing ongoing co-invention efforts. Working on the prototypes assists participants in verbalizing and explicating vague ideas; gestures can also often be utilized, such as pointing to and concretizing various aspects of the shared object (Viilo, Seitamaa-Hakkarainen and Hakkarainen 2018). Constant material enactment of ideas makes diverging intuitions apparent and pushes the participants, in a very concrete way, to strive toward shared understanding. Furthermore, materials use and product construction are likely to affect the division 
of labor (Yrjönsuuri, Kangas, Hakkarainen and Seitamaa-Hakkarainen 2019). Possession of particular tools such as shaping materials could, for instance, give the user the authority to control team activities (Buchholz et al. 2014; Rowell 2002). Thus, teachers should ensure that the construction responsibilities are delegated evenly and provide everyone a chance to participate in joint fabrication work.

The success of collaborative making is critically dependent on students actively engaging in and taking collective responsibility for the process (Kangas, Seitamaa-Hakkarainen and Hakkarainen 2013; Scardamalia and Bereiter 2014a). Although equal participation is beneficial, participants can still have various roles and relationships during the collaboration process (Mercier, Higgins, and da Costa 2014); some students can assume leadership roles, but their roles may vary during the project. Moreover, variations in interactional processes among students lead to more or less productive collaboration (Barron 2003). Most commonly, initiation and leadership roles entail delegating tasks, checking and following the given instructions, coordinating the attention of group members, and directing the tools and materials to be used. The exchange of ideas may both facilitate and hinder ideation and tinkering, which are dependent on the quality of a team's collaborative interaction (i.e., participants' engagement, social roles and relationships, etc.). It is also crucial that teachers or facilitators scaffold the making processes by sparking initial interests, introducing tools and materials, modeling and giving demonstrations, assisting students through frustrating moments, and organizing and facilitating teamwork (Gutwill et al. 2015; Svensson and Johansen 2019).

\section{Research aims}

The purpose of the present design-based study was to engage teams of seventh-grade students in collaborative making and develop methods for tracing their socially and materially mediated processes of co-invention. Ethnographic video and observation data were used to analyze how students engaged in longstanding collaborative making activities and how they took responsibility in the joint activities. The specific research questions guiding our investigations were as follows:

1. What was the general pattern of the teams' collaborative making processes across the coinvention projects? How did social-discursive and materially mediated aspects of making relate to one another?

2. How did the collaborative making processes interrelate with the co-inventions that the diverse student teams pursued?

3. How did each student team organize its collaborative making processes, and what was the teacher's role in the organization process?

\section{Research methods}

\section{Research setting}

The present design-based (Collins, Joseph, and Bielaczyc 2004) investigation was conducted by organizing a collaborative making project at a technology-emphasis lower-secondary school located in the capital area of Finland in spring 2017. All of the seventh-grade classes, 70 students in total, aged 13 to 14, participated in the project. The Finnish curriculum for basic 
education involves compulsory weekly craft lessons until the end of seventh grade, enabling us to implement collaborative making projects as a part of the regular curricular activity. The thematic design and making activities organized during the project enabled the bringing together of STEAM subjects. We engaged a team of two craft subject teachers and three other subject teachers (science, information and communication technology [ICT], and visual arts) to orchestrate the project. Moreover, eighth-grade students studying in technology-emphasis classrooms were invited to become digital-technology tutors to provide additional support in guiding the student participants (Tenhovirta, Korhonen, Seitamaa-Hakkarainen and Hakkarainen, submitted). In accordance with the Research-Practice Partnership (Coburn and Penuell 2016), researchers functioning within the frame of the Innokas-network (https://www. innokas.fi/en) familiarized the teachers and tutor-students with the socio-digital technologies and methods used and provided pedagogic support during the project.

The project involved giving student teams an open-ended co-invention challenge jointly designed by teachers and researchers: "Invent a smart product or smart garment by relying on traditional and digital fabrication technologies such as GoGo Board, other programmable devices, or 3D CAD." We use the term "co-invention" to refer to locally valued creative productions of the collaborative making process. Before the project, the eighth-grade tutor-students arranged a GoGo Board workshop for every participating class. The idea was to familiarize the students with the functional possibilities of the instruments and facilitate ideation about the use of programmable devices in the inventions (cf. Ching and Kafai 2008). GoGo Board is an open-source hardware device developed at the MIT Media Lab used for prototyping, educational robotics, science experiments, and environmental sensing. Due to the complexity of their invention projects, some teams ended up also using Adafruit Flora and Gemma. The actual co-invention project began in February 2017 with a two-hour ideation session arranged in collaboration with the Finnish Association of Design Learning. During this session, the students were asked, without consultation with the researchers, to self-organize into teams and develop preliminary ideas for their inventions. The relatively longstanding project involved eight to nine weekly collaborative making sessions (two to three hours per session) during March, April, and May 2017. To provide social recognition, the teams were also invited to present their co-inventions in two of our Invention Fairs held at the University of Helsinki in May 2017.

\section{Acquisition of the research data}

The data were acquired through ethnographic video research (Derry, Pea, Barron, Engle, Erickson, Goldman, Hall, Koschmann, Lemke, Sherin and Sherin 2010). We randomly selected two out of three classes with seven co-invention teams to be intensively followed by the first author. Each team's activities were video recorded separately using an individual GoPro action camcorder and a separate wireless lavalier microphone to document team discussions. The camera was placed on a floor-standing tripod positioned to capture a profile view from a high elevation in order to capture the team's actions as fully as possible. The first author was also present during every collaborative making session, making observations and taking written field notes to support in-depth analysis of the data. We also collected sketches and documents created by the teams and photographed the teams' prototypes and co-inventions. Five of the seven teams videoed were selected for the detailed analysis. One team was discarded because of a malfunctioning video device and another due to ethical issues within the team. For the analysis, parts of the video data that did not have analyzable action were removed. Table 1 summarizes the data analyzed. 
Table 1 A summary of the co-invention teams, the nature of the inventions, technologies used, and the video data analyzed

\begin{tabular}{|c|c|c|c|c|}
\hline Name & Members & Data (hh:mm) & Basic ideas for the co-inventions & Digital technologies used \\
\hline Bike & 3 boys & $14: 07$ & $\begin{array}{l}\text { A three-wheel bike that contains smart } \\
\text { technologies, such as an } \\
\text { environment responsive, } \\
\text { rechargeable LED lighting system }\end{array}$ & GoGo Board \\
\hline MGG & 4 boys & $13: 15$ & $\begin{array}{l}\text { Mobile Gaming Grip (MGG), a pair of } \\
\text { handles that improves the } \\
\text { ergonomics of a mobile phone } \\
\text { while playing games }\end{array}$ & $\begin{array}{l}\text { 3D CAD modeling, } \\
\text { 3D printing }\end{array}$ \\
\hline Moon & 6 girls & $13: 09$ & $\begin{array}{l}\text { A smart outfit for sports, including an } \\
\text { environment-responsive lighting } \\
\text { system to improve safety }\end{array}$ & $\begin{array}{l}\text { Adafruit Flora and Gemma, } \\
\text { light sensors, RGB LEDs }\end{array}$ \\
\hline UrPo & 6 boys & $12: 34$ & $\begin{array}{l}\text { A smart sole for sport shoes, including, } \\
\text { for example, an automatic warming } \\
\text { system for winter sports }\end{array}$ & $\begin{array}{l}\text { Adafruit Flora and Gemma, } \\
\text { temperature sensors }\end{array}$ \\
\hline Plant & 7 girls & $12: 21$ & $\begin{array}{l}\text { An automatic plant care system which } \\
\text { incorporates decorative elements }\end{array}$ & GoGo Board \\
\hline
\end{tabular}

The video data refer to actual data used in analyses, from which irrelevant interruptions (e.g., sections with no students visible) were eliminated

\section{Methods of data analysis}

As follows, we will explain the methods used to analyze data to answer each research question and explain in detail the Making-Process-Rug method developed in the context of the first research question. The data analyzed consisted of extensive video recordings of the making sessions of the five teams, approximately 12 to $14 \mathrm{~h}$ for each team, and about $65 \mathrm{~h}$ altogether. The collected video data were rich and dense, filled with social-interactive (i.e., verbal) and materially mediated (i.e., embodied) making actions. By adapting Ash's (2007) methodology, we analyzed the data across three stages corresponding, respectively, to the three levels (i.e., macro, intermediate, and micro) of our research questions. First, we developed the Making-Process-Rug method to analyze the macro-level patterns of the collaborative making process; second, we zoomed into the intermediated level to analyze the teams' co-inventions; and third, we focused on a micro-level examination of the teams' ways of organizing collaboration processes. Across the analyses, the results were compared to the first author's ethnographic observations and to the corresponding sections of the raw video data to verify and deepen the interpretations.

To answer the first research question regarding the general patterns of the teams' collaborative making process, we developed the visual Making-Process-Rug method. This analytic method was intended to make analyzable the massive amount of complex video data from the student teams' making processes. Our efforts in developing the method were also motivated by more than $500 \mathrm{~h}$ of making-process video data, to be reported elsewhere, collected from five schools across several years and grade levels. The analysis involved two stages: 1) systematic coding of the video data and 2) conversion of this data into a pictorial form, which enabled us to perceive the patterns of collaborative making processes and their flow as a whole (see Fig. 1). The videos were coded in three-minute segments using the ELAN multimedia annotator (4.9.4 and 5.0.0-beta) and a coding template driven by theories on the sociomaterial nature of collaborative making processes. 


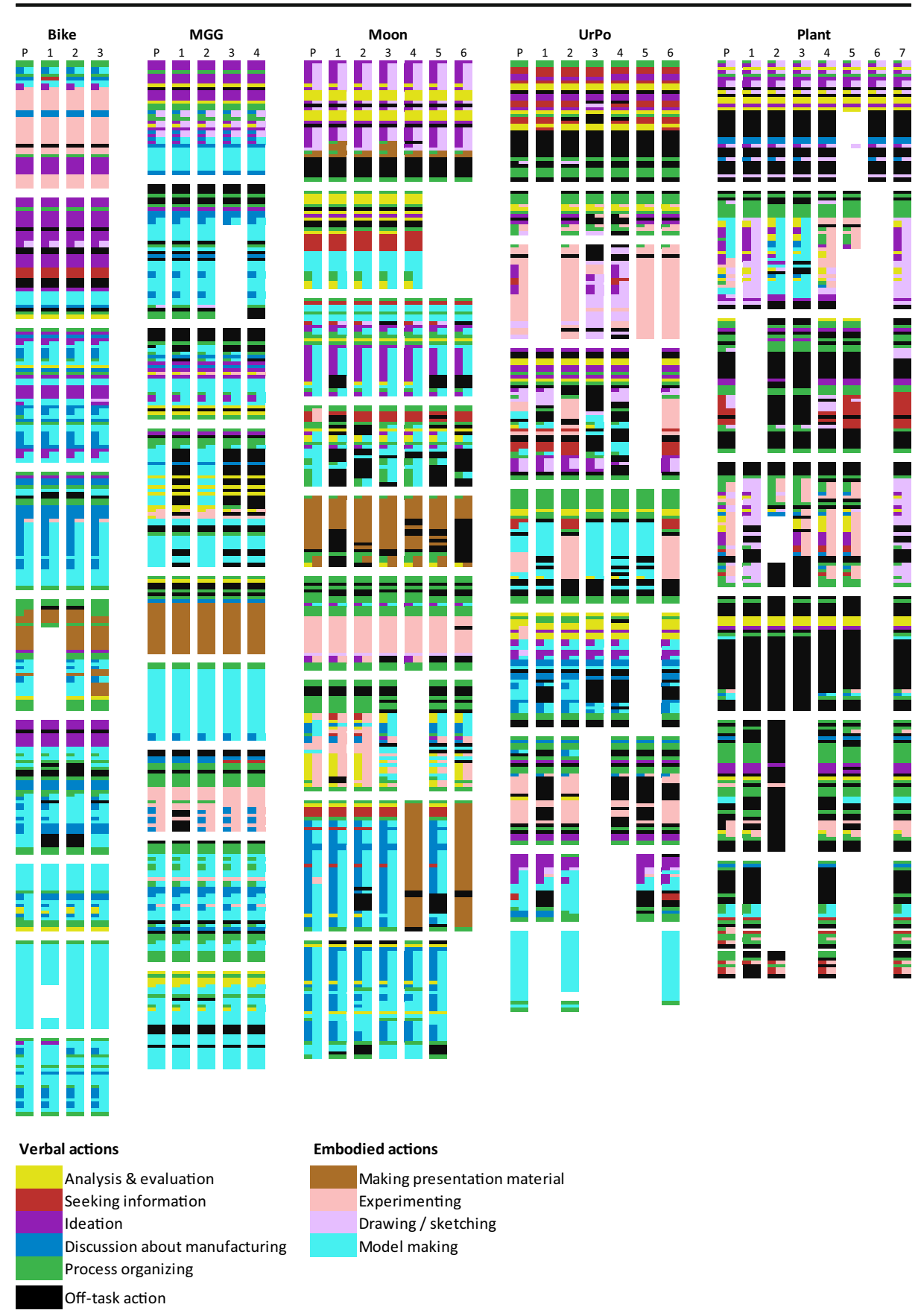

Fig. 1 Making-Process-Rug analyses of the teams' collaborative invention processes

Using a data visualization technique - to trace how knowledge-creating activities and discourses unfold over time and to provide visual aids for interpreting complex patterns - is not, however, a new approach in CSCL (Hmelo-Silver, Jordan, Liu, and Chernobilsky 2011; 
see also Law and Laferriére 2013). In fact, chronologically oriented representations of discourse and tool-related activity (CORDTRA) diagrams as well as "timeline graphs" of the INTERACT video-analysis program enable analyses that go beyond coding individual speech acts to provide a temporal and multimodal account of the interrelations among diverse discourse acts, scaffolds, representations, and usages of mediating tools (Hmelo-Silver and Barrows 2008; Hmelo-Silver et al. 2011; Kangas, Seitamaa-Hakkarainen and Hakkarainen 2013; Lahti, Seitamaa-Hakkarainen, Kangas, Härkki and Hakkarainen 2016; Viilo, SeitamaaHakkarainen and Hakkarainen 2018). In order to gain a comprehensive view of teams' making actions, Making-Process-Rug analysis relies, however, on fixed segmentation (three-minute) intervals, whereas CORDTRA analysis is based on discursive turns. We decided on threeminute segmentation on the basis of our initial explorations, experiences in our earlier video studies, and previous research on creative design and making (Lahti et al. 2016). The resolution of the unit of analysis is sufficient for revealing various design and making activities (for example, ideation, refining, analysis, and evaluation) and their iterations; simultaneously, it is not too detailed for the first stage of the analysis. Furthermore, the idea of the MakingProcess-Rug analysis is to use the first macro-level visualization to trace the chronological, overall processes in order to later zoom in for more detailed analyses of targeted events, such as process organizing. By using fixed segmentation and a systematic coding system adapted according to a study's purpose, the method also enables a determination of the quantitative aspects of collaborative making (e.g., the relative proportion of certain types of verbal or embodied making actions). With a very large amount of coded process data across schools, investigators may be able to conduct, for example, event-sequence analysis (Reimann 2009).

Table 2 describes categories used for coding the primary verbal and embodied making actions. Beyond theories of knowledge-creating learning and sociomateriality, the categories were based on design research, the Learning by Collaborative Design (LCD) model, and our earlier experiences investigating maker-centered learning (e.g. Kangas, Seitamaa-Hakkarainen and Hakkarainen 2013; Seitamaa-Hakkarainen, Viilo and Hakkarainen 2010). Primary verbal making actions were related to the themes of a team's discourse interaction (for example "we need to seek more information about LED lighting system and codes from the Internet"), which involved seeking information, discussing manufacturing, ideating and refining invention ideas, and organizing processes. Verbal actions were categorized according to discourse topics, whereas the coding of embodied making actions related to enacted doings. Embodied actions involved using digital or traditional tools and materials for sketching, making prototypes, experimenting with mechanical or digital solutions, and making presentation materials. The codes within each of the primary categories were mutually exclusive so that the segment could represent only certain primary verbal or embodied making actions, reflecting designrelated knowledge practices. Yet, the coding system allowed the co-occurrence of verbal and embodied making actions to be identified, which is interesting from the sociomaterial perspective (see Fig. 1).

For every segment, primary verbal and embodied making actions were determined for the whole team $(\mathrm{P})$ and each participant to identify possible subgroups of students. The nature of many making actions is such that often only one student may actively contribute; such is the case, for instance, in sketching and manufacturing. Yet, preliminary examinations revealed that students who did not directly perform the actual task were often still participating in action through epistemic and social engagement, evidenced during later stages of the process through their embodied actions, generation of new ideas, or evaluation of the work conducted. In the analysis, students' social engagement and identifiable focus of attention were used to 
Table 2 Structure of the coding template and code descriptions

\begin{tabular}{|c|c|c|}
\hline Code group & Code & Explanations and examples \\
\hline Description and notes & & $\begin{array}{l}\text { Written description of what the group was } \\
\text { talking about and doing }\end{array}$ \\
\hline \multirow[t]{6}{*}{ Primary verbal action } & & $\begin{array}{l}\text { Topic of the verbal interaction; only applied } \\
\text { if applicable }\end{array}$ \\
\hline & Seeking knowledge & $\begin{array}{l}\text { Seeking knowledge to find answers for } \\
\text { a problem related to the invention } \\
\text { or the process }\end{array}$ \\
\hline & Process organizing & Organizing the invention process \\
\hline & Analysis \& evaluation & $\begin{array}{l}\text { Analyzing or evaluating, e.g., knowledge, ideas, } \\
\text { functionality, or constraints }\end{array}$ \\
\hline & Ideation & $\begin{array}{l}\text { Generating and proposing new ideas or further } \\
\text { developing previously presented ideas }\end{array}$ \\
\hline & Discussion about manufacturing & $\begin{array}{l}\text { Discussing issues directly related to } \\
\text { manufacturing, e.g., tools or making } \\
\text { technique }\end{array}$ \\
\hline \multirow[t]{5}{*}{$\begin{array}{l}\text { Primary embodied } \\
\text { making action }\end{array}$} & & $\begin{array}{l}\text { Focusing on actual doings; only applied if } \\
\text { applicable }\end{array}$ \\
\hline & Drawing/sketching & Constructing external visual representations \\
\hline & Experimenting & $\begin{array}{l}\text { Testing, e.g., digital features, programming, } \\
\text { features of materials, or the stability } \\
\text { of a structure }\end{array}$ \\
\hline & Making presentation material & Creating, for instance, an invention poster \\
\hline & Model making & Constructing prototypes \\
\hline Off-task action & Off-task & $\begin{array}{l}\text { Engaging in activities unrelated to the } \\
\text { invention project, with no primary making } \\
\text { actions being conducted }\end{array}$ \\
\hline \multirow[t]{3}{*}{ Student $1 \ldots \mathrm{n}$ : } & & $\begin{array}{l}\text { Applied separately for each student, numbered } \\
\text { from } 1 \text { onwards }\end{array}$ \\
\hline & Present & The student is present in the making session. \\
\hline & Absent & The student is absent from the making session. \\
\hline \multirow[t]{3}{*}{ Teamwork } & All together & $\begin{array}{l}\text { All team members present in the session } \\
\text { work together }\end{array}$ \\
\hline & Divided & $\begin{array}{l}\text { For divided team work, four additional codes } \\
\text { were added, where applicable. }\end{array}$ \\
\hline & Sub-team $1 \ldots n$ & $\begin{array}{l}\text { Each sub-team was defined separately using the } \\
\text { student numbers delimited using commas, } \\
\text { e.g., sub-team 1: } 1,3 \text { and sub-team } 2: 2,4 \text {. }\end{array}$ \\
\hline
\end{tabular}

determine their involvement in making actions and, consequently, their part in the subgroup of students in question; the data were coded accordingly. Further, if a team discussed off-task issues while actively making a prototype, the segment was coded as model making rather than as an off-task action.

Four investigators took part in coding the data. The Moon and Plant teams' MakingProcess-Rugs were coded by two independent investigators, ensuring the reliability of the coding procedures. After the coding process, all segments containing no action (e.g., waiting for a teacher to arrive to give obligatory instructions for the safe use of tools or waiting for computers to open or update) were removed from the video data. The final adjusted usable video data consisted of $65 \mathrm{~h}$ and $27 \mathrm{~min}$ of coded team session videos in total. When completed, the analysis produced color-coded, layered diagrams that we refer to as ProcessRugs because of their resemblance to woven rag rugs (see Fig. 1). The data also enabled us to quantitatively compare the patterns of teams' collaborative making processes. 
The second research question focused on examining the student teams' co-inventions in relation to their collaborative making. In this intermediate level of analysis, we utilized results from the first analysis, field notes, as well as visual and other documentation to construct indepth descriptions of each team's making process, the epistemic object pursued, and resulting co-invention. Some aspects of the teams' processes that were included in the findings, such as motivation and enjoyment, were based on the ethnographic observations of the first author. The case descriptions helped us characterize the teams' making activities and reflect on the interrelations with technologies and tools used. Furthermore, we also addressed how the composition of the groups appeared to affect the collaborative making process.

To answer the third research question, regarding how co-invention teams organized their collaborative making processes, we performed a more detailed visual Process-Organizing-Rug analysis of the teams' ways of co-regulating or organizing the collaboration processes. All three-minute segments of the video data coded to represent process organizing were retrieved from the data. Process organizing represented verbal actions where team members negotiated mutual responsibilities, talked about what should be done next, and analyzed the specific tools and programs needed in the next stage. Subsequently, the sample material was recorded using a more refined minute-lengthed segmentation, which focused on the team members' and teachers' roles in organizing the collaborative making process. The analysis facilitated the identification of topics in process organizing, students' and teachers' roles across the entire coinvention process, and teachers' involvement in organizing the making process. For every oneminute segment, the topic of was determined. The team members doing the organizing were specified, and it was noted whether the organizing was supported by the teacher. The topic of process organizing was divided into three categories: 1) organizing making activities covering the discursive aspects of doing or performing something, including discussion concerning next steps, such as 3D-modeling, sewing fabric, or searching for more information about coding LED lights; 2) constraint and resources, including discussions on how to find certain materials, scheduling future activities, or acquiring social resources such as help from a teacher; and 3) teamwork, covering how various tasks would be divided or shared among team members. We also coded for the organizer (i.e., the individual who initiated the need to organize the process).

\section{Results}

In the following, we will present our findings in accordance with our research questions. We will start by characterizing the macro-level patterns of the making process, subsequently examine the student teams' co-inventions in relation to collaborative making processes, and, finally, provide a detailed account of enacted process organizing.

\section{Making-process-rug analysis of the general pattern of collaborative making processes}

We investigated the extensive collaborative making process that the students engaged in to coinvent complex artifacts over a period of four months. The co-invention challenge was to invent a smart product or a smart garment using digital and traditional making technologies. The primary verbal and embodied making actions of the Bike, MGG, Moon, UrPo, and Plant teams were traced using the Making-Process-Rug method. The resulting systematic process visualizations of the teams' collaborative making processes are presented in Fig. 1. From the figure, it can be seen that discursive (verbal) and materially mediated (embodied) activity were 
intertwined and occurred successively throughout the process, depending on the advancement of the project.

$\mathrm{P}=$ teams' primary verbal and embodied making actions; $1 \ldots \mathrm{n}=$ actions of individual team members. In stripes where both verbal and embodied actions occur simultaneously, the verbal action is presented on the left side of the segment and the embodied action on the right. The three-minute stripes stacked together form making sessions. Sessions are separated with a blank horizontal stripe, with the first session being on top, and a timeline flowing from top to bottom. Blank columns indicate that the participant was absent. (see Appendix).

Figure 1 reveals that the Making-Process-Rugs of the teams varied considerably according to emphasis on different verbal and embodied making actions. Visual inspection also reveals that the collaborative making processes of the Moon, Urpo, and Plant teams were somewhat more fragmented than those of Bike and MGG. Further, it appears that off-task (black color) activities were more common in larger groups (6-7 members), specifically the Moon, UrPo and Plant teams, than in the compact Bike and MGG teams. The larger teams appeared to have problems engaging all team members in working consistently to advance a shared epistemic object. Beyond team size, group dynamics and the nature of the inventions may have also affected the observed differences. Furthermore, visual analysis clearly reveals the importance of model making in the successful completion of the making process; this can be seen from the successive occurrence of the light turquoise color in Fig. 1. In the Bike, MGG, Moon, and Urpo teams' processes, model making was the most prominent activity that intertwined with ideation, with discussion about manufacturing (dark blue), analysis, and evaluation occurring either in parallel or successively with model making. The analysis revealed this pattern of intertwining model making and focused verbal actions to be the most important factor in successful co-invention. Our ethnographic observations further supported this finding and gave insight into how these actions together led to the successful co-inventions of the Bike, MGG, Moon, and Urpo teams. The discursive activities of ideation, analysis, and evaluation assisted participants in determining new design problems and proposing solutions to existing ones. Model making fostered the generation of new, often more detailed design ideas, which appeared to advance the co-invention process. Furthermore, model making gave the proposed solution a concrete form, enabling evaluation and acceptance or rejection of the prospective solution. Finally, model making integrated the ideas and solutions and materialized all aspects of the team's co-invention. Sociomaterial engagement, both in materially mediated making action and in focused discourse interaction to solve emerging invention challenges, is critical in co-inventing tangible artifacts.

The Plant team did not engage in model making, and the team spent most of its working time on off-task actions (the color black dominated their Making-Process-Rug), to the extent that some sessions were spent almost entirely doing off-task activities. Their making actions were very short, and the team shifted very often to off-task actions. They experimented, for example, with materials and digital tools, but based on the visual analysis, these experiments did not lead to model making, and, thus, the potential to advance their co-invention never materialized. The team did some sketching but overall produced only a few separate objects that had no functionality. The periods of embodied making actions were longer and more coherent in the Bike and MGG teams than in Moon and Urpo, with relatively little off-task time. In the case of MGG, off-task actions were usually related to waiting or taking a short break after a period of epistemic work. Some students drifted to off-task activities in the Moon and UrPo teams, causing some scattering of the collaborative making processes. The embodied making actions also varied from team to team due to the differences between the co-inventions 
and fabrication methods. However, all successful teams followed the pattern of intertwined and alternating phases of model making and discursive design actions.

In order to confirm the results of the above Making-Process-Rugs visual analyses, we examined the coded video data quantitatively to determine the distribution of the teams' verbal and embodied making actions across the whole co-invention process. Table 3 presents the proportions for the three most prevalent verbal and embodied making actions, as well as those for off-task actions.

Table 3 reveals that the proportion of verbal actions varied from $30.2 \%$ to $44.4 \%$. The Plant team spent $35.4 \%$ of their overall activities on verbal actions; this is close to the average proportion of these actions among the successful teams $(\bar{x}=37.6)$. However, the quantitative analysis confirmed the previous result of the Making-Process-Rug analysis: the biggest differences between the Plant team and the successful teams were in model making. The Plant team only spent $6.1 \%$ on model making, whereas the lowest proportion of the successful teams' model making was $16 \%$ (UrPo). When model making is combined with experimenting, the difference is even more prominent. Successful teams spent between $33.1 \%$ and $48.5 \%$ $(\mathrm{x}=39.8 \%)$ of their overall embodied making actions on model making and experimenting, whereas the Plant team only spent $16.3 \%$ of their embodied making actions on these activities. It must also be noted that although the UrPo team had nearly as high a proportion of off-task activities, they still managed to carry out a successful project; pursuit of shared epistemic object enabled to group to quickly regroup to do their work after periods of some team members' off task activity.

The quantitative analysis indicated that social-discursive and materially mediated aspects of making had to be intertwined to develop functional inventions. To advance the sociomaterial making process, it is critical that the embodied making actions and focused discursive activities (e.g., ideation, discussion of manufacturing) entangle with one another (Kafai, Ah, Fields, Ristin and Searle 2014; Kangas, Seitamaa-Hakkarainen and Hakkarainen 2013; Mehto

Table 3 Proportions of the teams' verbal, embodied, and off-task actions across the invention processes

\begin{tabular}{|c|c|c|c|c|c|}
\hline \multirow[b]{2}{*}{ Activities } & \multicolumn{5}{|l|}{ Team } \\
\hline & Bike & MGG & Moon & UrPo & Plant \\
\hline \multicolumn{6}{|l|}{ Verbal actions } \\
\hline Ideation & 11.5 & 5.5 & 6.9 & 8.4 & 7.4 \\
\hline Discussion about manufacturing & 15.8 & 9.2 & 15.5 & 2.8 & 2.5 \\
\hline Process organizing & 11.4 & 14.7 & 11.2 & 10.4 & 16.2 \\
\hline Analysis \& evaluation & 1.5 & 5.0 & 7.3 & 3.9 & 5.9 \\
\hline Seeking information & 1.0 & 0.3 & 3.5 & 4.7 & 3.4 \\
\hline Proportion of all verbal actions (A) & 41.2 & 34.7 & 44.4 & 30.2 & 35.4 \\
\hline \multicolumn{6}{|l|}{ Embodied making actions } \\
\hline Experimenting & 5.4 & 6.4 & 7.3 & 17.1 & 10.2 \\
\hline Making presentation material & 4.1 & 4.2 & 10.8 & 0.0 & 0.0 \\
\hline Model making & 43.1 & 35.9 & 28.0 & 16.0 & 6.1 \\
\hline Drawing / sketching & 0.7 & 1.9 & 3.8 & 7.6 & 12.6 \\
\hline Proportion of all embodied making actions (B) & 53.4 & 48.4 & 49.9 & 40.7 & 28.9 \\
\hline Proportion of all task-related actions $(\mathrm{A}+\mathrm{B})$ & 94.6 & 83.1 & 94.3 & 70.9 & 64.3 \\
\hline Proportion of all off-task action & 5.4 & 16.9 & 5.7 & 29.1 & 35.7 \\
\hline Total & 100.0 & 100.0 & 100.0 & 100.0 & 100.0 \\
\hline
\end{tabular}

The proportion of all task-related action was determined by summing A and B together. The horizontal rows provide comparative proportions of different making activities across the teams 
et al. 2020). The relative proportions of respective verbal and embodied making actions appear to depend on the nature of the co-invention being pursued. The Bike and Moon teams had to solve challenging manufacturing issues, whereas MGG and UrPo proceeded more straightforwardly to fabrication. Furthermore, the proportion of embodied making actions such as model making (Bike, MGG, Moon, UrPo) and experimentation (UrPo, Moon, MGG) played an important role in the creation of adequate co-inventions.

\section{Pursuit of invention through the student teams' collaborative making processes}

To answer the second research question concerning the co-inventions that the student teams aimed to make, we will describe each team's making process in detail. Relying on all the process data, including participant observations and artifacts, we will describe each team's epistemic object and the participants' associated co-invention processes.

\section{Team bike}

The co-invention of the Bike team was a three-wheeled bike containing an environmentresponsive, rechargeable LED lighting system utilizing the GoGo Board. The team's epistemic object was from the very beginning to create a three-wheeled bike, although its envisioned features evolved considerably. During the first project sessions, the team members conducted mechanical experiments involving possible structures for their bike and built a small model of it (Fig. 2). Working out the mechanics of the wheels and the LED lighting system required iteration and experimentation. Based on their experiments and knowledge found on the Internet, they refined their ideas intensively, especially during the second working session, where purple color dominates the second session of their Making-Process-Rugs. The MakingProcess-Rugs reveal an iterative process of testing ideas and then developing them further across the subsequent sessions. Toward the end of the project, they crystalized their idea and concentrated mostly on the model making. They used several initially unfamiliar advanced fabrication methods, such as welding and metal lathe turning. Simultaneously, they considered the final product and its mechanics, deliberated on materials and structures, and organized their process. Thus, the team actively worked with emerging epistemic and practical challenges throughout the process. The Bike team was highly engaged in making and worked through the whole process in an intensive, co-driven manner, even when encountering epistemic or

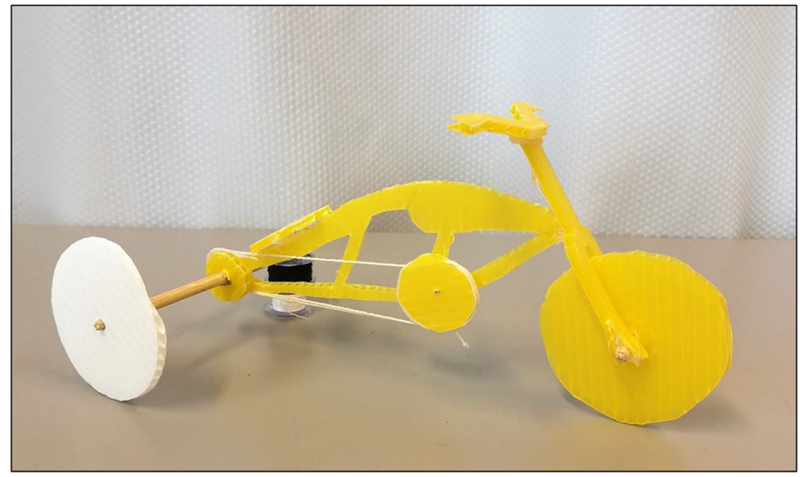

Fig. 2 Bike team's first prototype 
practical challenges. Even the few occasions that the students spent working either alone or in smaller teams could be regarded as moments of collaborative effort because they first agreed upon separate activities together and kept each other informed on their progress.

\section{Team MGG}

The MGG team's epistemic object was a mobile gaming grip; the team invented a pair of handles to improve the ergonomics of mobile phones in gaming contexts (see Fig. 3 for a sketch). Their preliminary idea was to have two separate handles, using adapters for audio and charger connections, and to use $3 \mathrm{D}$ printing as a method of making. Their co-invention process had two stages: First, they built a prototype from basic materials such as wood, rubber, and masking tape (Fig. 4), and then, from session six onwards, they focused on creating 3D CAD models based on the first prototype. Prototyping triggered more refined ideas about shape, size, structure, mounting, and connections of the object. When building the prototype, the team members worked iteratively with their epistemic object, generating, testing, evaluating, and refining their ideas for improving the ergonomics and usability of the handles across different smart phones. Their overall process highlights the importance of model making, although the final fabrication method was a 3D CAD model, and later a 3D printed model. After initial failures with using SketchUp, they experimented with three other 3D CAD programs and selected both Tinkercad and SketchUp for the modeling, finally finding themselves able to produce a printer-ready 3D model of the handles. The Making-Process-Rugs reveal that, similarly to the Bike team, the MGG team spent most of its time on the project on modelmaking activities, including making the $3 \mathrm{D}$ models. Within-team collaboration was maintained even when tasks were divided and the participants worked in smaller sub-teams or alone.

\section{Team moon}

The Moon team relied on e-textiles in the making process, and their epistemic object consisted of inventing an environment-responsive outfit for sports (cf. Litts, Kafai, Lui, Walker and Widman 2017). See Fig. 5 for their sketch. Adafruit Flora functioned as a wearable electronic platform and programmable NeoPixel LED functioned as light components. The team members crystalized

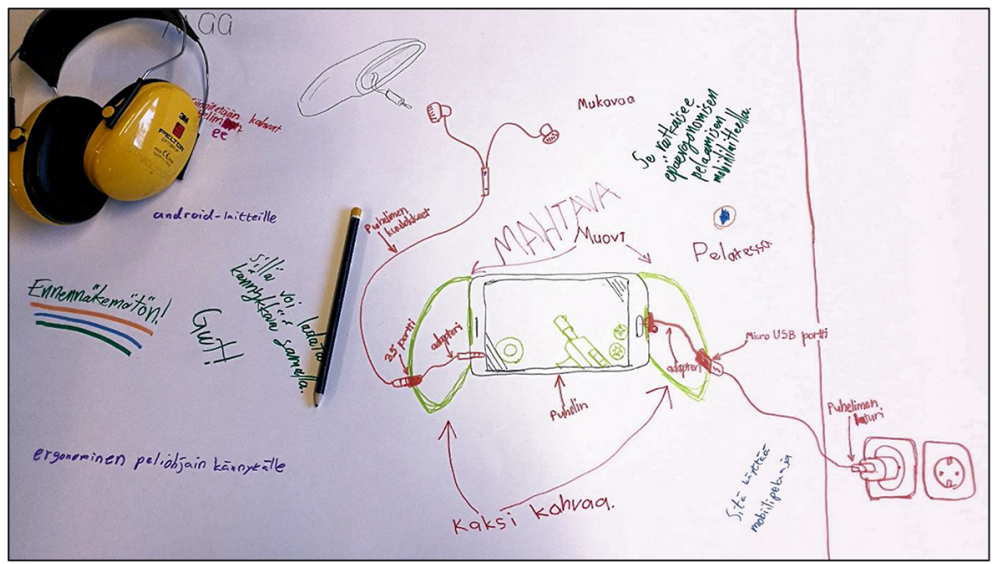

Fig. 3 Sketch from the MGG group 


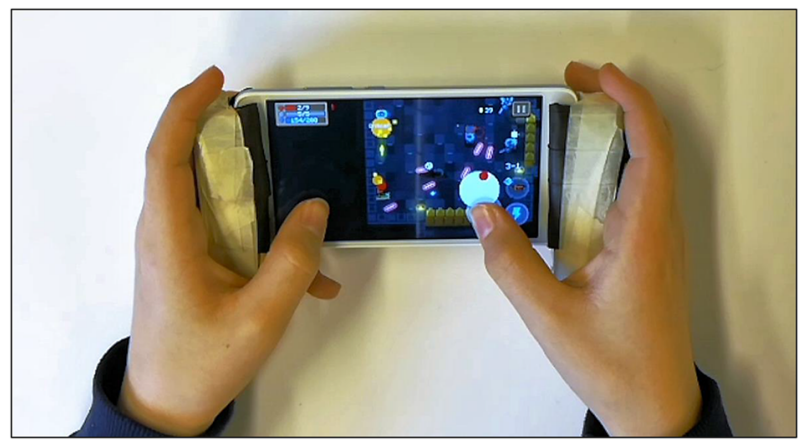

Fig. 4 First prototype of the MGG team in use

their co-invention ideas and started pattern making for the clothing in the first session while still continuing to elaborate further ideas related to sensors, lighting systems, and implementation. For example, they planned carefully how to place the LED lights and the microcontrollers on the clothes, so that the electronic circuits would be functional, the lights would be visible from all angles when worn, the components would not rub or push against the skin to create discomfort, and the lights would create an aesthetically pleasing design. Subsequently, the team engaged in three separate but partially interlinked activities novel to the team: sewing the clothing from elastic material, programming and assembling the electronics, and making presentation materials for their product. The team's materially mediated style of working with the epistemic object and generating design ideas can be seen directly from the Making-Process-Rugs. During the first session, the ideas emerged and were refined through sketching. Due to the complexity of Arduino programming, the team also spent the majority of two sessions on model making and

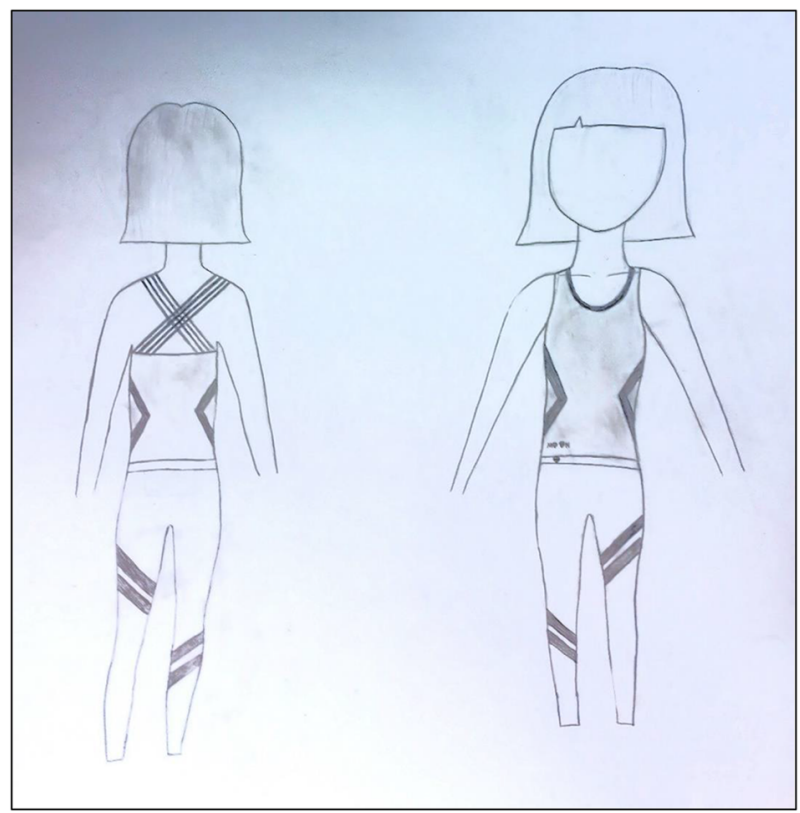

Fig. 5 Sketch of the Moon team's outfit 
digital experimentation. Because of the visual orientation of their invention, the team invested more time than the other teams in making presentation materials (see Table 3 and the MakingProcess-Rugs). During the model making, the team members were in constant verbal contact with each other, refining their ideas, discussing the manufacturing, and evaluating its outcomes. The Moon team was highly focused on its epistemic object, and all team members engaged in on-task, co-making activity. Observations and the Making-Process-Rugs reveal a slight scattering of the collaboration during periods of ideation, evaluation, and refining ideas, which are important for making decisions; nevertheless, the team appeared overall to keep its focus on the shared epistemic object.

\section{Team UrPo}

The UrPo team's epistemic object was to invent a smart insole for sports shoes, using Adafruit Flora and Gemma as electronic platforms to produce the functionalities (cf. Litts et al. 2017). See Fig. 6 for their first sketch. Creating the temperature sensor-controlled warming system for the insole was challenging, but the team designed the functionality from scratch using resistance wire. During the co-invention process, they also considered using other sensors, but ideas remained vague and were not implemented. The team produced numerous sketches and prototypes of various insoles, experimenting with alternative ways of placing the Adafruit Gemma board on the insole (Fig. 7). The Making-Process-Rugs revealed that the UrPo team's making process was more scattered than those of the other successful teams. Nevertheless, the team engaged in a truly iterative making process, creating ideas and models, testing them in action, and prototyping solutions and digitally experimenting with them. Students 2 and 6 formed "the backbone" of the team, assuming responsibility for the most challenging epistemic aspects of the process (i.e., programming, advanced model making, and tests conducted with resistance wire). Nevertheless, the team usually made decisions through joint collaboration, and the entire group felt joint ownership of the co-invention.

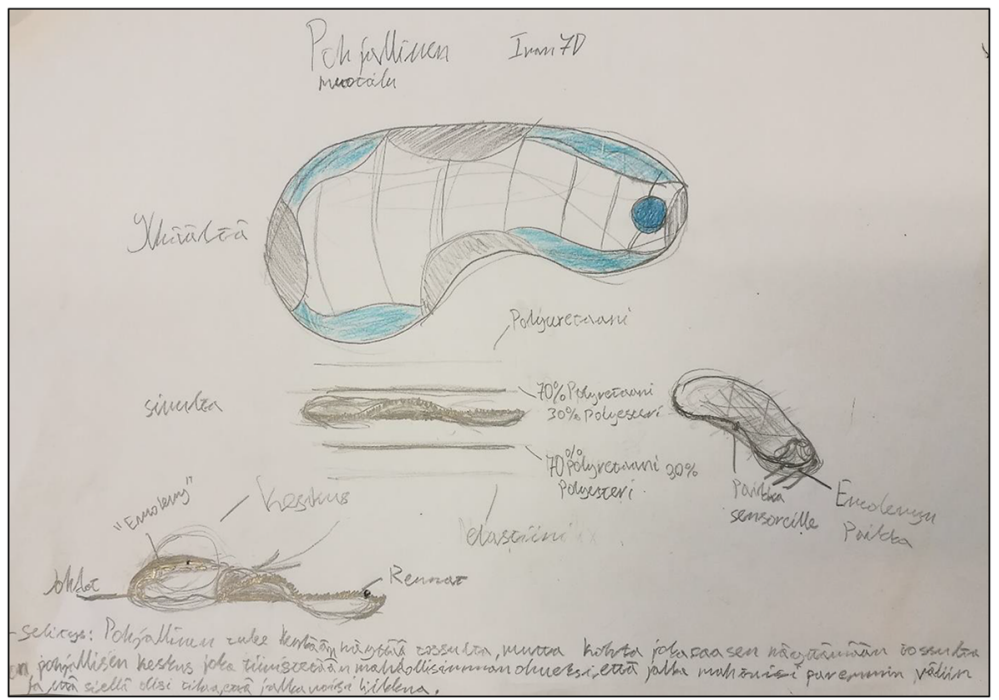

Fig. 6 Sketch of the UrPo insole 


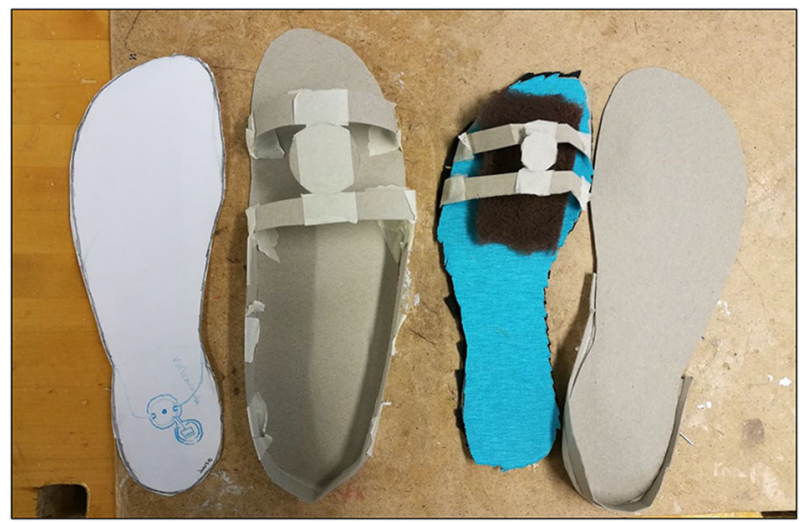

Fig. 7 Insole prototypes made by the UrPo team

\section{Team plant}

The Plant group intended to build a plant care system that also served as a decorative element. However, the Making-Process-Rugs reveal that their process was very scattered and did not lead to refinement of the epistemic object or the production of prototypes as material instantiations of their ideas. The prominent making practice was sketching, but their colorful drawings lacked the refinement needed to contribute to the co-invention. Figures 8 and 9 present, respectively, the team's first and latest sketches, which appear relatively similar. In comparison with the successful teams, the Plant team's lack of model making was remarkable (see Table 3 and the Making-Process-Rugs). The making activities in the last four sessions occurred mainly when the teacher or a tutor was present in the group. The participants were guided to make tests using the GoGo Board and later with a possible power supply and pump system, but they did not fully engage in these activities and mostly left the work to the eighthgrade tutor-students. The team's ability to collaborate may have been diminished because dominant students 2 and 3 were the ones engaging in mostly off-task activities. Team members worked briefly in pairs on an individual aspect of the invention, but due to the lack of teamlevel collaboration their ideas were never integrated, and no epistemic object was generated that could have advanced the co-invention process.

To conclude, the Bike, MGG, Moon, and UrPo teams participated productively in the collaborative co-invention project, although coming up with successful solutions required overcoming both social-epistemic and material-technological challenges. The analyses indicate that both success and collaboration within teams resulted when the team members shared the same envisioned epistemic object. The members of the Bike and MGG teams shared their respective epistemic objects, and refined them through experimentation and model making throughout the invention process. Although the Moon and UrPo teams' invention processes appeared sometimes scattered, sketching, prototyping, and experimentation assisted them in advancing their respective shared epistemic objects. In contrast with the successful teams, the Plant team did not work out a comprehensive epistemic object and, consequently, their efforts remained scattered and the invention did not advance. These results highlighting the epistemic importance of embodied making (e.g., prototyping, materials, and experimentation) are in accordance with earlier research (Blikstein 2013; Kafai 1996; Kafai et al. 2014; Kangas, 


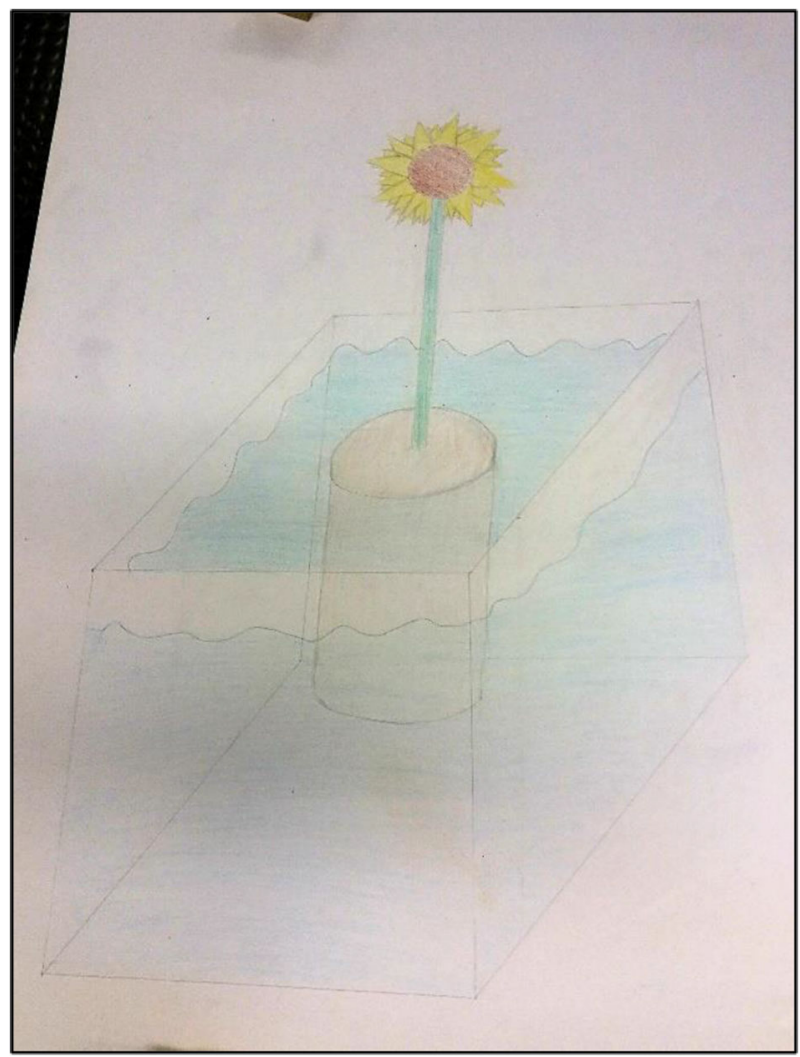

Fig. 8 The first sketches of the Plant team

Seitamaa-Hakkarainen and Hakkarainen 2013). Next, we will take a closer look at each team's ways of organizing the collaborative making process.

\section{Process organizing during collaborative making processes}

To answer the third research question concerning the teams' practices of organizing their collaborative making processes, we carried out a second level of video analysis that involved zooming in on the micro-level discursive efforts at organizing collaboration processes. The resulting color-coded, layered diagrams, or Process-Organizing-Rugs, are presented in Fig. 10, in which one stripe represents one minute of video data. In the analysis, we identified team members who actually conducted the process organizing through their verbal actions, often supported with embodied actions (e.g., simultaneous pointing to or handling of tools and materials). The Process-Organizing-Rugs reveal the topic of the organizing, who conducted it, and the involvement of the teacher in it. The rugs represent only the segments coded as process organizing. The colors signify the purpose of the process organizing: 1) organizing making activities by discussing how to conduct relevant tasks, such as welding or sewing outfit parts together (orange); 2) addressing constraints and resources (green), such as considering the amount of time needed to complete certain working phases or the materials, tools, or assistance needed; and 3) organizing teamwork (blue), such as agreeing about the division of labor. 


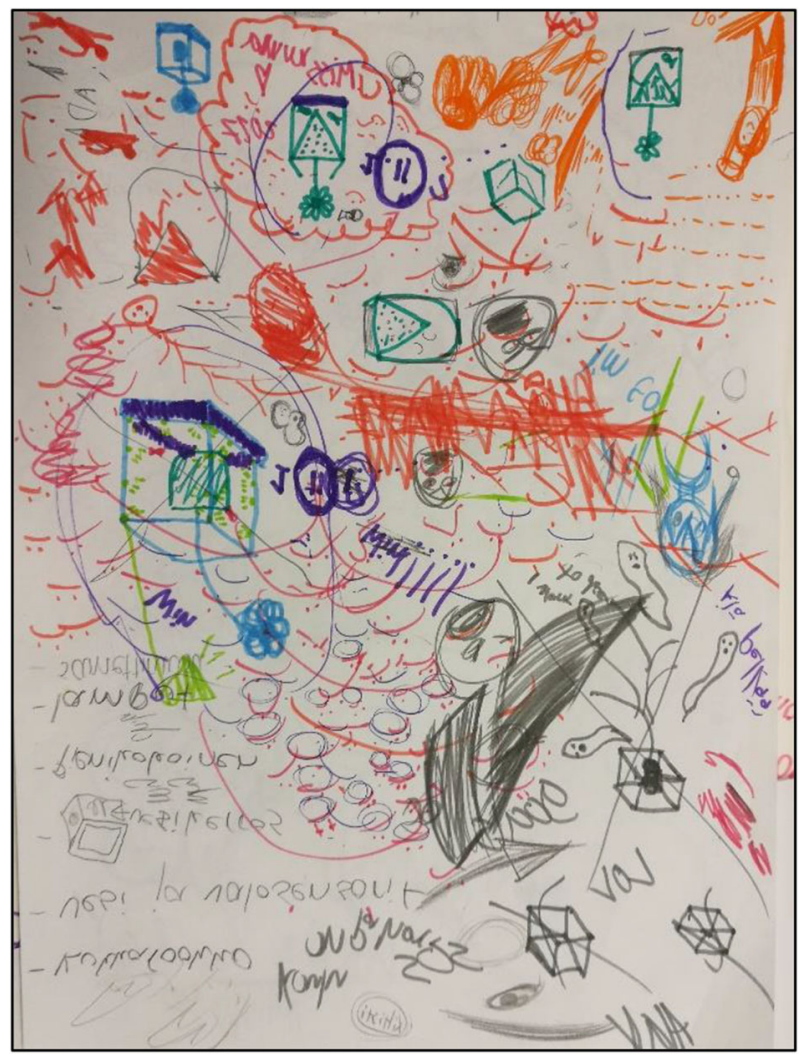

Fig. 9 The Plant team's later sketch

The Bike team focused mainly on organizing making activities and teamwork. During the first session, the team determined how to get the materials and resources needed. From there, the process organizing mainly alternated between organizing making activities and agreeing about the division of labor. In accordance with the Bike team's tight collaboration, the process organizing was predominantly performed in close collaboration among all team members. Further, the lack of teacher involvement was striking in this highly autonomous team. The teachers were only needed to provide material resources and guidance regarding fabrication, such as welding, techniques. The Bike team's co-driven process organizing was characterized by joint project management, continuous shared responsibility, and mutual control of different aspects of the multifaceted project. In the following extract, the team simultaneously addresses three different aspects of the project: 1) what needs to be done to advance the project (swap a $\operatorname{cog}$ from one wheel to another); 2) how to ensure smooth continuation of the project (gathering all loose parts to one place); and 3) division of labor.

3: Next we'll have to detach the front wheel from that [points to a bike] but it doesn't have...we'll have to take the cog from this cause that wheel doesn't have a cog [points to a cog in a loose wheel that he is holding].

1: True 

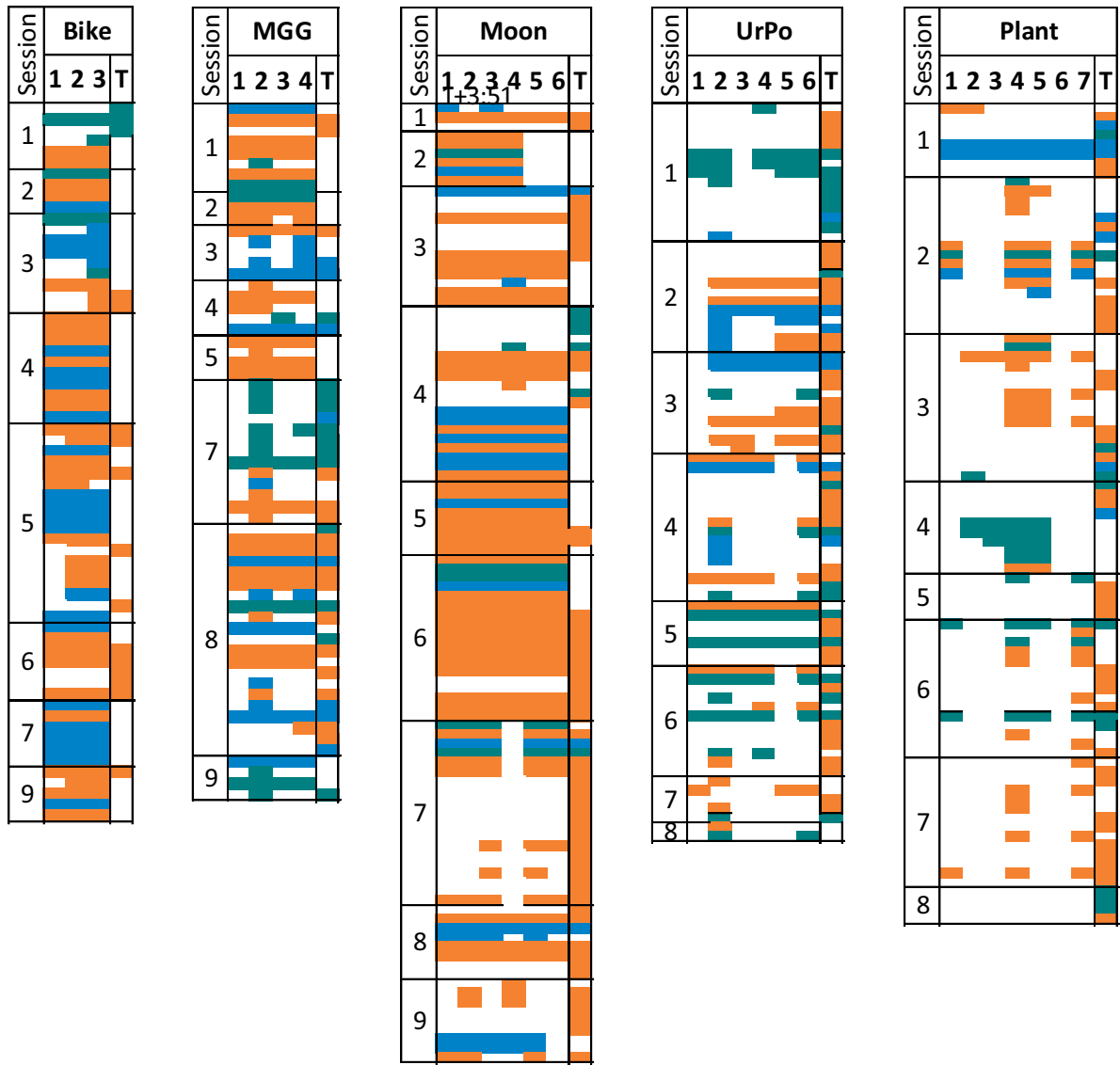

Making activities

Constraints and resources

Teamwork

Fig. 10 The teams' Process-Organizing Rugs represent only the segments of the video data that were coded as process organizing. Time flows from top to bottom in every rug. One stripe represents one minute of video data, and the colors signify the purpose of the process organizing: making actions, constraints and resources, or teamwork. The team members are marked with the numbers. The teacher is marked with T; the teacher rug indicates teacher involvement in the process organizing

3: We'll have to detach and put this cog to that.

2: Hey, is it ok for you guys if we put all loose parts here? [starts gathering loose parts and putting them on a table]

3: 2, can you help me with this if 1 takes off the front wheel from that and we have to detach this cog?

1: Shouldn't we just take off the back wheel? [instead of the front wheel]

3: But the front wheel is in better condition, look...

1: Oh yes, this back wheel is very worn out.

[The entire team gets to work.]

The MGG team addressed making activities and teamwork-related issues in their efforts at process organizing. Due to the novel nature of their invention, the team had to invest more 
effort in addressing the constraint- and resource-related issues than the other teams. Overall, the team assumed shared responsibility of its making activity and functioned as one unit. Yet, student 2 had a leading role in process organizing. Even though this student usually initiated the process, he gave the other team members opportunities to participate. Occasionally, the team deliberately sought a teacher's assistance in deciding how to proceed. The teacher's role in the team's project organization was to guide the fabrication (3D printing) process, provide resources, and assist with project management. Despite active participation of the teacher, the team maintained control throughout the project. The following extract reveals how the teacher guided the team through joint discussions of the process organizing:

T: One of you could really start to make the $3 D$ modelling. Your design isn't that complicated, is it?

3: Yes, ok.

T: I can go and see if there are some of those eighth grade tutor-students available. They haven't been participating in $3 D$ modelling though...

2: No.

T: And then I know one student from the ninth grade that maybe knows $3 D$ modelling.

2: Yep, but I don't think the tutors can help much cause they haven't been involved in this.

T: Yes.

2: Doesn't the 3D printer come with a software that is easier to use, with which we could do it straight away.

T: Yes, it does, but all these programs that were installed to the laptops can be used directly with our $3 D$ printer. It is in fully working condition now. And you don't have to do such a complicated design that you can't model it. Experiment at least. I will get laptops for you. Experiment and we'll see how it goes.

4: If we need to make those holes... [to the 3D model]

2: There is another program in addition to Blender, it might be easier.

T: And then there is SketchUp.

2: We can't really use SketchUp.

4: Well, I think I can do it. It's just quite difficult.

The Moon team's process organizing was mainly concentrated on organizing making activities. Although the team was large, processes were organized in a very collaborative manner through negotiations within the whole team. On a few occasions, student 4 took a more leading role in cases where quick practical decisions were needed to continue working without interruptions. Field notes revealed that the group needed the teacher's support mainly to a) get new materials or tools and b) learn unfamiliar working methods, such as making clothes from elastic materials, constructing e-textiles, and organizing teamwork around these activities. The following extract illustrates the team's dialogic process organizing and demonstrates their ability to consider different aspects of the process simultaneously. They also composed subteams to conduct certain tasks.

4: We need to plan to where the LEDs will be attached, and someone needs to go to do the programming.

2: Is it only one of us, who goes to do the programming?

1: It can't be just one of us alone. 
3: No, I think it's three and three [students].

2: Yes, three and three.

3: Who will go to do the programming?

2: I think we three will go [indicates herself and students 1 and 5]. We did it the last time as well. I don't remember anything about it though.

5: Me neither but we'll go anyway.

In the UrPo team, process organizing was partially delegated to students 2 and 6, whose efforts carried the process forward despite the other members' off-task activities. These two students took the main responsibility for process organizing, instead of the entire team taking responsibility for the process. Because of the complexity of the co-invention and the scattered making process, the teacher was needed to organize their process and occasionally adopted a more controlling approach. The teacher's expertise was also needed to make the resistance wire function and to program the system. For example, the teacher guided the team on how to determine the length of the resistance wire, using electronics testing equipment available in the classroom to warm it up enough but not overheat. It is notable that when the teacher was helping to organize the process, student 2 and/or student 6 were always involved. Overall, UrPo team's process organizing can be characterized as led by the team leaders and supervised by the teacher. The following extract reveals a situation in which the teacher supervising the project steps in; student 2 then starts delegating tasks to other team members with the support of student 6 .

T: [stops the off-task conversation between team members 1, 3, 4, and 5] Now you have such a big task that every one of you is needed. I will bring you some materials soon.

2: You all should do at least one more like this [shows a template of a foot to others]. We need many of them.

T: Yes, everyone should have their own so they can design and test them.

2: Who continues with this? [shows the ready-made template of the foot to others]

1: That's 3's, so...

2: You can continue with this [hands the foot template to 3].

3: You mean do a prototype?

2: Yes.

3: $O k$.

2: And the rest of you invent something. It doesn't have to be like this.

6: Yes, it doesn't have to be like this, but something.

2: Everyone one of you four makes their own prototype... a prototype of your ideas.

The Plant team's Process-Organizing-Rug is strikingly different from those of the other teams. It was rare that the entire team — or even a majority of members - took part in process organizing. Only students 4 and 7 (sometimes student 5) consistently participated in process organizing, whereas some others did not take part in it at all. On one occasion, student 2 stated, "If we sit here like this, it looks like we are discussing the project." Consequently, the teacher had to occasionally give the team direct instructions to return to work and provide suggestions for what to do next. However, organizing processes from the outside was challenging; identifying a productive direction is dependent on the team making the required inventions and associated decisions. Furthermore, the dominant students did not resume these organizing actions and did not assume leading roles corresponding to those of key members of the UrPo team. The following extract illustrates the unsuccessful attempts to organize the process: 
After four minutes of off-task actions:

7: We don't know what we are doing. When do we really start searching for the right

parts? The plan was to build the watering system. We need a pump.

4: What do we need the pump for? We don't need that.

7: We need it for the actual prototype.

4: What are we doing?

7: We were told that we should build this...

[giggling]

7: We need the GoGo Board or something...

The team doesn't engage in the conversation, and team members 4 and 7 resume the off-task activities.

To conclude, organizing collaboration processes appears especially important as well as challenging in nonlinear co-invention projects where the objects, productive directions of efforts, and intermediate steps are not known beforehand. The successful teams managed to sort out most of the teamwork challenges themselves, and they addressed related issues in almost every session. The Plant team was not able to organize its invention process and was not very engaged in the project.

\section{Discussion}

The present investigation analyzed five student teams' collaborative making processes, in which traditional and digital fabrication technologies were used to invent materially embodied artifacts. The Making-Process-Rug method was developed to gain a macro-level visual understanding of the patterns of the making process, and the Process-Organizing-Rug analysis was conducted to zoom in for micro-level level analysis regarding the teams' ways of organizing extensive invention efforts and teamwork. Although the methodological choice to rely on a rather coarse level of segmentation afforded a comprehensive view of the lengthy co-invention process, it is possible that short moments of ideation or evaluation could, for instance, have been overridden by more prominent, longer-lasting actions. Nevertheless, the method revealed the iterative nature of the successful collaborative making processes and highlighted the importance, and intertwined nature, of verbal actions, materiality and embodied making. The Process-Organization-Rugs, in turn, enabled a more refined analysis of students' teamwork and teachers' scaffolding of various aspects of process organizing. Simultaneously, it is important to keep in mind that the present data were collected from a particular school with a long tradition of technology-mediated learning and teaching; as such, the findings cannot be generalized across other schools and settings.

The first research question addressed the general pattern of the teams' collaborative making process during the co-invention project. One critical aspect of success in the co-invention process appeared to be engagement in embodied actions rather than mere discussion about vague ideas. Model making and experimentation were especially helpful in integrating ideas and solutions and enabling the materialization of invention ideas. The successful groups created sophisticated design ideas, produced elaborate visualizations and prototypes, and tested and refined their epistemic objects of invention. Thus, sociomaterial engagement, both in materially mediated making and focused discourse for solving emerging challenges, appears to be critical in co-inventing tangible artifacts. Although the importance of tools and embodied 
aspects of learning have often been emphasized (Hmelo-Silver et al. 2011; Jeong 2013), the present study highlights the active, agentic role of materiality and argues for deeper understanding of sociomaterial entanglement in CSCL.

The second question examined the interrelations between the collaborative making process and the nature of the students' inventions. The inventions examined relied on various fabrication methods, digital devices, materials, and functionalities. The iterative pursuit of a shared epistemic object was prominent in every successful co-invention team. In accordance with earlier research, the concretization and materialization of the epistemic object were critically dependent on such aspects of embodied making as prototyping, experimentation, and model making (Blikstein 2013; Kafai et al. 2014; Kangas, Seitamaa-Hakkarainen and Hakkarainen 2013).

The third question considered the teams' ways of organizing their collaborative making processes. Success in the collaborative creation of knowledge appeared to be critically dependent on students who actively engaged in and collectively took responsibility for the co-invention process. This importance of active engagement is in accordance with previous research (Damsa, Kirscher, Andriessen, Erkens, and Sins 2010; Kangas, Seitamaa-Hakkarainen and Hakkarainen 2013; Scardamalia and Bereiter 2014a). The successful, more compact teams, Bike and MGG, pursued nonlinear invention processes in an iterative and self-organizing manner (Yrjönsuuri, Kangas, Hakkarainen and Seitamaa-Hakkarainen 2019) and organized their making and team activities in practically every session. Even though some students played leading roles in process organizing in MGG, Moon and UrPo, the teams retained team collaboration and a supportive atmosphere. The teachers' participation in the process organizing in these cases was mostly instigated by the teams' need for materials and guidance in technical working methods. While the teacher's guidance was dialogic rather than strongly directive in the well-functioning teams, it was directive in the case of the Plant team. It appeared, however, pretty difficult for the teachers to provide sufficient scaffolding and real-time coaching for nonlinear invention processes without commitment from the team to advance its epistemic object.

The present process visualizations enable portrayals of the temporal and dynamic trajectories of collaborative making processes (Hmelo-Silver et al. 2008; Lehesvuori, Viiri, Rasku-Puttonen, Moate and Helaakoski 2013) and the epistemic objects being pursued. The specific advantage of the Making-Process-Rug method is simultaneous tracing of social-discursive and materially embodied aspects of maker-centered learning to analytically capture the sociomaterial entanglement of making processes (Mehto et al. 2020). For example, how conceptual and materially embodied aspects of knowledge creation interlink during co-invention processes. Following Ash's (2007) methodology of video analysis, our approach first provides the big picture of the collaborative processes and then zooms in on the events critical for tracing students' joint regulation of teamwork activities. Depending on the focus of the study, the zooming in can also focus, for example, on teachers' scaffolding activities within the teams. In our related studies, we have zoomed in on the epistemic role of materiality in the invention process (Mehto et al. 2020). We have also tracked the participatory actions and detected the relevant materials involved in these actions (Mehto, Riikonen, Kangas and Seitamaa-Hakkarainen, in press). Studies in progress address epistemic (idea advancement) as well as socio-emotional aspects of making. We believe that the present visual-analytic methods can provide a useful instrument for other investigators 
of maker-centered learning. For example, which they might use to analyze computational thinking in action or emotional experiences related to making processes.

In accordance with post-humanist approaches, our study highlights the central role of materially mediated artifact construction in student teams' enacted collaborative making activity. Many investigators have developed sophisticated methods for multilevel tracing of CSCL in general and the role of digital instruments in particular (e.g., Hmelo-Silver, Jordan, Liu, \& Chernobilsky, 2011). The present investigation expands on earlier studies by working out systematic methods for tracing sociomaterial aspects of maker-centered learning. Our investigation suggests that embodied processes of sketching, prototyping, and model making do not just assist thinking processes, but play a crucial epistemic role in terms of supporting ideation, explication of vague ideas, building shared meanings, finding of productive lines of advancement, and coming up with novel innovations. Hence, materially mediated activity appears to play a crucial agentic role in collaborative knowledge creation. The material aspects seem to intertwine with discursive activities without being reducible to the latter (Mehto et al., 2020). In spite of the material mediation involved in technologyenhanced learning, many investigators of the field foreground either conceptual (Scardamalia \& Bereiter, 2006) or intersubjective (Andriessen, Baker, \& Suthers, 2003) aspects of CSCL; the materiality of collaborative learning appears at least partially to be "missing in action" (Orlikowski \& Scott, 2008). Learning-by-making research appears to necessitate taking the "interobjective" (Latour, 1996) stance, characteristics of actor-network theory, calling for more symmetric treatment of humans and artifacts and sensitivity to the active roles of artifacts and other nonhuman actors in learning processes (Stahl \& Hakkarainen, in press). The sociomaterial processes involved in creating materially mediated artifacts have, however, seldom been addressed or analytically captured. Although further methodological development and collection of data across diverse contexts are certainly needed, the MakingProcess-Rug analysis appears to advance the field by enabling systematic tracing of social and material aspects of students' knowledge-creating learning.

Furthermore, the present investigation reveals that significant aspects of maker culture can be productively integrated with the regular curricular activity of schools. Maker projects may be implemented through integrative STEAM projects, elective courses, and collaboration with external makerspaces, when craft studies are not available. It is educationally valuable to engage young students in using traditional and digital fabrication technologies for collaborative design, invention, and joint making of artifacts, and overcoming associated epistemic, engineering, and practical challenges. The present successful teams clearly appropriated design-related knowledge practices, such as, ideation, making of prototypes, and experimentation with digital solutions. Although the multi-professional teacher team could have also fostered appropriation of scientific practices, that aspect of making was not afforded sufficient structured support. Arguably, teachers' expertise in design, fabrication methods, mechanics, materials, and the pedagogics of invention and making is crucial when conducting these types of knowledge-creating projects (cf. Linn 2006). Because not all teachers are already skilled in making technologies, we emphasize the importance of engaging a multi-professional teacher team for orchestrating making projects and jointly overcoming technical and practical challenges encountered (Härkki, Vartiainen, Seitamaa-Hakkarainen, \& Hakkarainen, in press). In the present case, the craft education teachers and the eighth-grade tutor-students played a crucial role in the 
successful completion of the co-invention project; their guidance enabled student participation in the advanced making processes. The students who completed successful coinvention projects will be engaged as peer-tutors in programmable devices, 3D CAD modeling, and 3D printing for the next cohort of student-inventors (Tenhovirta, Korhonen, Seitamaa-Hakkarainen and Hakkarainen, submitted). Participatory methods, characteristic of the research-practice partnership (Coburn and Penuel, 2016) established, have also allowed us to engage teacher practitioners, who were initially unfamiliar with the maker technologies, in the numerous maker projects we have initiated. Together with rigorous research, partnering with teachers, students, and other educational stakeholders this will assist expanding maker-centered learning across schools.

Acknowledgements This research was supported by the Academy of Finland [Grants 286837 and 331763] and Strategic Research Council of the Academy of Finland [grant 312527].

Funding Open access funding provided by University of Helsinki including Helsinki University Central Hospital.

\section{Appendix}

Because of the complexity of the patterns in question, the interpretation of Fig. 1 is explained in the figure caption, as well as through a separate example (Fig. 2). By examining the Making-Process-Rugs, the actions of each team member and the primary verbal and embodied making actions for the team can be determined for each three-minute segment. To assist in the interpretation of Fig. 1, we present a sample of the Making-Process-Rugs for the Moon team's seventh sessions (Fig. 11). The figure reveals an intertwining of discursive and embodied making processes. The session starts from the top. Student 4 was absent from this particular session, and therefore her column is empty. At the beginning of the session, the team organizes the process for six minutes but drifts to off-task actions for the following nine minutes. After this, the team returns to process organizing for the next $15 \mathrm{~min}$, although on two occasions students 3, 5, and 6 conduct off-task actions for three minutes. Subsequently, the team divides, and students 1 and 2 begin seeking knowledge and conducting digital experiments, whereas students 3, 4, and 5 engage in model making and, simultaneously, analyze, evaluate, and discuss the manufacturing of the model. One stripe of these intertwined actions in support of the advancement of the invention process is described in detail in Fig. 11. The session continues with varying activities and finally ends with process organizing by all the team members present in the session.

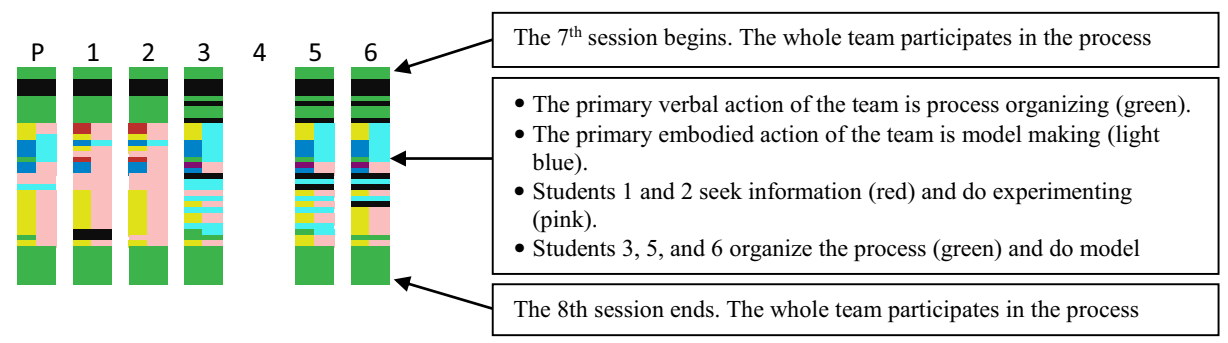

Fig. 11 Team Moon's seventh and eighth sessions 
Open Access This article is licensed under a Creative Commons Attribution 4.0 International License, which permits use, sharing, adaptation, distribution and reproduction in any medium or format, as long as you give appropriate credit to the original author(s) and the source, provide a link to the Creative Commons licence, and indicate if changes were made. The images or other third party material in this article are included in the article's Creative Commons licence, unless indicated otherwise in a credit line to the material. If material is not included in the article's Creative Commons licence and your intended use is not permitted by statutory regulation or exceeds the permitted use, you will need to obtain permission directly from the copyright holder. To view a copy of this licence, visit http://creativecommons.org/licenses/by/4.0/.

\section{References}

Andriessen, J., Baker, M., \& Suthers, D. (Eds.). (2003). Arguing to learn: Confronting cognitions in computersupported collaborative learning environments. Dordrecht, Netherlands: Kluwer.

Ash, D. (2007). Using video data to capture discontinuous science meaning making in nonschool settings. In R. Goldman, R. Pea, B. Barron, \& S. J. Derry (Eds.), Video research in the learning sciences (pp. 221-240). New York: Routledge.

Barron, B. (2003). When smart groups fail. The Journal of the Learning Sciences, 12(3), 307-359.

Bereiter, C., \& Scardamalia, M. (2003). Learning to work creatively with knowledge. In E. de Corte, L. Verschaffel, N. Entwistle, \& J. Van Merriënboer (Eds.), Powerful learning environments: Unravelling basic components and dimensions (pp. 55-68). London: UK: Elsevier.

Blikstein, P. (2013). Digital fabrication and 'making' in education: The democratization of invention. In C. Büching \& J. Walter-Herrmann (Eds.), FabLab: Of machines, makers and inventors (pp. 203-222). Bielefeld: Transcript.

Buchholz, B., Shively, K., Peppler, K., \& Wohlwend, K. (2014). Hands on, hands off: Gendered access in crafting and electronics practices. Mind, Culture, and Activity, 21(4), 278-297.

Ching, C. C., \& Kafai, Y. (2008). Peer pedagogy: Student collaboration and reflection in a learning-throughdesign project. The Teachers College Record, 110(12), 2601-2632.

Clapp, E. P., Ross, J., Ryan, J. O., \& Tishman, S. (2016). Maker-centered learning: Empowering young people to shape their worlds. New York: Jossey-Bass.

Collins, A., Joseph, D., \& Bielaczyc, K. (2004). Design research: Theoretical and methodological issues. The Journal of the Learning Sciences, 13, 15-42.

Coburn, C. E., \& Penuel, W. R. (2016). Research-practice partnership in education. Educational Researcher, 45, 48-54.

Damsa, C. I., Kirscher, P. A., Andriessen, J. E. B., Erkens, G., \& Sins, P. H. M. (2010). Shared edpistemic agency: An empirical study of an emergent construct. Journal of the Learning Sciences, 19, 143-186.

Derry, S. J., Pea, R. D., Barron, B., Engle, R. A., Erickson, F., Goldman, R., Hall, R., Koschmann, T., Lemke, J., Sherin, M., \& Sherin, B. L. (2010). Conducting video research in the learning sciences: Guidance on selection, analysis, technology, and ethics. Journal of the Learning Sciences, 19(1), 3-53.

Ewenstein, B., \& Whyte, J. (2009). Knowledge practices in design: The role of visual representations as 'epistemic objects'. Organization Studies, 30(1), 7-30.

Forsström, H., Korhonen T., Tiippana, N., Sormunen, K., Juuti, K., Seitamaa-Hakkarainen, P., Lavonen, J., \& Hakkarainen, K. (submitted). Tracing students' socio-digital ecology: Learning through socio-digital participation inside and outside of school. A manuscript submitted for publication.

Gutwill, J. P., Hido, N., \& Sindorf, L. (2015). Research to practice: Observing learning in tinkering activities. Curator: The Museum Journal, 58(2), 151-168.

Halverson, E. R., \& Sheridan, K. (2014). The maker movement in education. Harvard Educational Review, 84(4), 495-504.

Hakkarainen, K. (2009). A knowledge-practice perspective on technology-mediated learning. International Journal of Computer Supported Collaborative Learning, 4(2), 213-231.

Hietajärvi, L., Lonka, K., Hakkarainen, K., Alho, K., \& Salmela-Aro, K. (2020). Are schools alienating digitally engaged students? Longitudinal relations between digital engagement and school engagement. Frontline Learning Research, 8(1), 33-55.

Hmelo-Silver, C., \& Barrows, H. S. (2008). Facilitating collaborative knowledge building. Cognition and Instruction, 26(1), 48-94.

Hmelo-Silver, C., Jordan, R., Liu, L., \& Chernobilsky, E. (2011). Representational tools for understanding complex computer-supportive collaborative learning environments. In S. Puntambekar, G. Erkens, \& C. 
Hmelo-Silver (Eds.), Analyzing interactions in CSCL: Methods, approaches and issues (pp. 83-106). London: Springer.

Honey, M., \& Kanter, D. (2013). Introduction. In M. Honey \& D. Kanter (Eds.), Design, make, play: Growing the next generation of STEM innovators (pp. 19-24). London: Routledge.

Härkki, T., Vartiainen, H., Seitamaa-Hakkarainen, P., \& Hakkarainen, K. (in press). Co-teaching in non-linear projects: A contextualized model of co-teaching to support educa-tional change. Teaching and Teacher Education.

Ito, M., Gutiérrez, K., Livingstone, S., Penuel, B., Rhodes, J., Salen, K., Schor, J., Sefton-Green, J., \& Watkins, S. C. (2013). Connected learning: An agenda for research and design. Irvine, CA: Digital Media and Learning Research Hub.

Jeong, H. (2013). Development of group understanding via the construction of physical and technological artifacts. In D. Suthers, K. Lund, C. Penstein Rosé, C. Teplovs, \& N. Law (Eds.), Productive multivocality in the analysis of group interaction (pp. 331-351). London: Springer.

Järvelä, S., Järvenoja, H., Malmberg, J., \& Hadwin, A. F. (2013). Exploring socially shared regulation in the context of collaboration. Journal of Cognitive Education and Psychology, 12(3), 267-286.

Kafai, Y. (1996). Learning through artifacts: Communities of practice in classrooms. AI \& SOCIETY, 10(1), 89100.

Kafai, J. (2006). Constructionism. In K. Sawyer (Ed.), The Cambridge handbook of the learning sciences (pp. 35-46). Cambridge, MA: Cambridge University Press.

Kafai, Y., Ah, D., Fields, A., Ristin, K., \& Searle, A. (2014). Electronic textiles as disruptive designs: Supporting and challenging maker activities in schools. Harvard Educational Review, 84(4), 532-556.

Kangas, K., Seitamaa-Hakkarainen, P., \& Hakkarainen, K. (2013). Design thinking in elementary students' collaborative lamp designing process. Design and Technology: an International Journal, 18(1), 30-43.

Knorr-Cetina, K. (2001). Objectual practice. In K. K. Cetina, T. R. Schatzki, \& E. Von Savigny (Eds.), The practice turn in contemporary theory (pp. 175-188). London: Routledge.

Lahti, H., Seitamaa-Hakkarainen, P., \& Hakkarainen, K. (2004). Collaboration patterns in computer-supported collaborative designing. Design Studies. Vol., 25(4), 351-371.

Lahti, H., Seitamaa-Hakkarainen, P., Kangas, K., Härkki, T., \& Hakkarainen, K. (2016). Textile teacher students' collaborative design processes in a design studio setting. Art, Design and Communication in Higher Education, 15(1), 35-54.

Latour, B. (1996). On interobjectivity. Mind, Culture and Activity, 3(4), 228-245.

Law, N., \& Laferriére, T. (2013). Multivocality in interaction analysis: Implications for practice. In D. Suthers, K. Lund, C. Penstein Rosé, C. Teplovs, \& N. Law (Eds.), Productive multivocality in the analysis of group interaction (pp. 683-699). London: Springer.

Lehesvuori, S., Viiri, J., Rasku-Puttonen, H., Moate, J., \& Helaakoski, J. (2013). Visualizing communication structures in science classrooms: Tracing cumulativity in teacher-led whole class discussions. Journal of Research in Science Teaching, 50(8), 912-939.

Linn, M. C. (2006). The knowledge integation perspective on learning and instruction. In R. K. Sawyer (Ed.), The Cambridge handbook of the learning sciences (pp. 243-264). New York: Cambridge University Press.

Litts, B. K., Kafai, Y. B., Lui, D. A., Walker, J. T., \& Widman, S. A. (2017). Stitching codeable circuits: High school students' learning about circuitry and coding with electronic textiles. Journal of Science Education and Technology, 26(5), 494-507.

Mehto, V., Riikonen, S., Hakkarainen, K., Kangas, K., \& Seitamaa-Hakkarainen, P. (2020). Epistemic roles of materiality within a collaborative invention project at a secondary school. The British Journal of Educational Technology, 51, 1246-1261.

Mehto, V., Riikonen, S., Kangas, K., \& Seitamaa-Hakkarainen, P. (in press). Sociomateriality of collaboration within a small team in secondary school maker centered learning. International Journal of Child Computer Interaction.

Mercier, E. M., Higgins, S. E., \& da Costa, L. (2014). Different leaders: Emergent organizational and intellectual leadership in children's collaborative learning groups. International Journal of Computer-Supported Collaborative Learning, 9(4), 397-432.

Miyake, N., \& Kirschner, P. A. (2014). The social and interactive dimensions of collaborative learning. In R. K. Sawyer (Ed.), The Cambridge handbook of the learning sciences (pp. 418-438). Cambridge: Cambridge University Press.

Orlikowski, W., \& Scott, S. W. (2008). Sociomateriality: Challenging the separation of technology, work and organization. The Academy of Management Annals, 2, 433-474.

Paavola, S., Lipponen, L., \& Hakkarainen, K. (2004). Modeling innovative knowledge communities: A knowledge-creation approach to learning. Review of Educational Research, 74, 557-576.

Panadero, E., \& Järvelä, S. (2015). Socially shared regulation of learning: A review. European Psychologist, 20, 190-203. 
Papert, S. (1980). Mindstorms: Children, computers, and powerful ideas. New York: Basic Books.

Peppler, K., Halverson, E., \& Kafai, Y. B. (Eds.). (2016). Makeology. New York: Routledge.

Reimann, P. (2009). Time is precious: Variable and event-centered approaches to process analysis in CSCL research. International Journal of Computer-Supported Collaborative Learning, 4, 239-257.

Ritella, G., \& Hakkarainen, K. (2012). Instrument genesis in technology mediated learning: From double stimulation to expansive knowledge practices. International Journal of Computer-Supported Collaborative Learning, 7, 239-258.

Rowell, P. M. (2002). Peer interactions in shared technological activity: A study of participation. International Journal of Technology and Design Education, 12(1), 1-22.

Scardamalia, M., \& Bereiter, C. (2014a). Knowledge building and knowledge creation: Theory, pedagogy, and technology. In K. Sawyer (Ed.), The Cambridge handbook of the learning sciences (2nd ed., pp. 397-417). New York: Cambridge University Press.

Scardamalia, M., \& Bereiter, C. (2014b). Smart technology for self-organizing processes. Smart Learning Environments, 1(1), 1-13.

Seitamaa-Hakkarainen, P., Viilo, M., \& Hakkarainen, K. (2010). Learning by collaborative designing: Technology-enhanced knowledge practices. International Journal of Technology and Design Education, 2(2), 109-136.

Seitamaa-Hakkarainen, P., \& Hakkarainen, K. (2017). Learning by making. In Peppler (2017) The SAGE encyclopedia of out-of-school learning (pp. 421-424). Thousand Oaks, California: SAGE.

Silander, P., Riikonen, S., Seitamaa-Hakkarainen, P., \& Hakkarainen, K. (in press). Learning computational thinking in phenomenon-based co-creation projects - Perspectives from Finland. In S.-C. Kong \& H. Abelson (Eds.), Computational thinking education in K-12: Artificial intelligence literacy and physical computing. Cambridge, MA: The MIT Press.

Stahl, G., \& Hakkarainen, K. (in press). Theories of CSCL. To appear. In U. Cress, C. Rose, S. Wise, \& J. Oshima (Eds.), International handbook of computer supported collaborative learning. London: Springer.

Svensson, M., \& Johansen, G. (2019). Teacher's didactical moves in the technology classroom. International Journal of Technology and Design Education, 29(1), 161-176.

Tenhovirta, S., Korhonen, T., Seitamaa-Hakkarainen, P., \& Hakkarainen, K. (submitted). Cross-age peer tutoring in a technology-enhanced STEAM project at a lower secondary school. A manuscript submitted for publication.

Viilo, M., Seitamaa-Hakkarainen, P., \& Hakkarainen, K. (2018). Teacher's long-term orchestration of technology-mediated collaborative inquiry project. Scandinavian Journal of Educational Research, 62, $407-432$.

Yrjönsuuri, V., Kangas, K., Hakkarainen, K., \& Seitamaa-Hakkarainen, P. (2019). The roles of material prototyping in collaborative design process at an elementary school. Design and Technology Education: an international journal, 24(2), 141-162.

Publisher's note Springer Nature remains neutral with regard to jurisdictional claims in published maps and institutional affiliations. 